\title{
Local perspectives and context in relation to feeding practices of children under 2 years in the mountain villages of northern Thailand
}

\author{
Anna Roesler ${ }^{1, *}$, Lisa G Smithers ${ }^{1}$, Pattanee Winichagoon ${ }^{2}$, \\ Prasit Wangpakapattanawong ${ }^{3}$ and Vivienne Moore ${ }^{1,4,5}$ \\ ${ }^{1}$ School of Public Health, Level 9, Adelaide Health and Medical Sciences Building, Mail Drop DX 6500550, The \\ University of Adelaide, Adelaide, SA 5005, Australia: ${ }^{2}$ Institute of Nutrition, Mahidol University, Salaya, \\ Phutthamonthon, Thailand: ${ }^{3}$ The Knowledge Support Center for the Greater Mekong Sub-region (KSC-GMS), Faculty \\ of Science, and the World Agroforestry Centre (ICRAF), Chiang Mai University, Chiang Mai, Thailand: ${ }^{4}$ Fay Gale \\ Centre for Research on Gender, University of Adelaide, Adelaide, SA, Australia: ${ }^{5}$ Robinson Research Institute, \\ University of Adelaide, Adelaide, SA, Australia
}

Submitted 2 March 2018: Final revision received 21 June 2018: Accepted 2 July 2018: First published online 17 August 2018

\begin{abstract}
Objective: To gain an in-depth understanding of infant and young child feeding practices, accompanying beliefs and their sociocultural context in the Karen and Lua ethnic communities of northern Thailand.

Design: A two-day workshop and thirty in-depth interviews were undertaken in June 2014. Dialogue occurred with the assistance of translators and was recorded, transcribed and translated. A detailed thematic analysis was undertaken.

Setting: Northern Thai indigenous communities in which one-third of the children under 5 years of age are stunted.

Subjects: People with various roles in the local health system and twenty-six villagers who cared for infants and young children.

Results: Predominant breast-feeding was said to occur for 1 to 3 months but was not exclusive due to early introduction of water and/or rice. Exclusive breastfeeding for 6 months was impeded by the need for mothers to return to farming work, with the early introduction of solids enabling infants to be cared for by other family members. Low variety in complementary foods was typical during infancy, with few local foods having appropriate texture and special preparation of foods rarely described. A pervasive underlying issue is women's responsibility to labour and lack of time to care for their young children. Poverty and food insecurity also featured in participants' accounts.

Conclusions: In combination, women's limited time to care, poverty and food insecurity are perpetuating poor nutrition of children in early life. Agricultural solutions that are being explored should also attend to the burden of work for women.
\end{abstract}

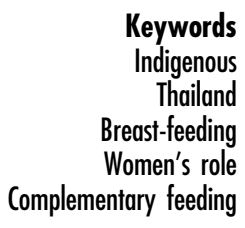

Undernutrition in the first 24 months following birth can result in delayed growth and development that is difficult to reverse, so good nutrition during this period is of utmost importance. Proximal causes of undernutrition from birth to 24 months are non-exclusive breast-feeding and inappropriate complementary feeding practices ${ }^{(1)}$.

Undernutrition has been reported repeatedly in children in the hill tribes of northern Thailand ${ }^{(2-4)}$. ('Hill tribes' is a translation of the official term used by The Ministry of Thailand, Chao Khao, and is not considered disrespectful.) In 2013, one-third of children in the Karen and Lua ethnic communities in the district of Mae Chaem were stunted ${ }^{(5)}$, a much higher prevalence than the national rural average of $8 \%{ }^{(6)}$. Food insecurity and poverty have been identified as underlying causes of undernutrition in these communities ${ }^{(7)}$ which are remote, with roads frequently unpassable in the monsoon season. Historically, villagers lived by subsistence farming, more recently growing maize as a cash crop and sometimes selling animals.

The WHO and UNICEF have made recommendations to improve young children's nutrition, including exclusive breast-feeding (EBF) for the first 6 months, after which safe, 
nutritionally adequate, age-appropriate and responsive complementary feeding should commence ${ }^{(8,9)}$. Recently the UN General Assembly announced a 'Decade of Action on Nutrition' from 2016 to 2025, to address malnutrition and food insecurity. Governments are asked for a commitment to addressing undernutrition of children under 5 years of age. This global effort is supported in Thailand.

Extended duration of breast-feeding is well documented in Thailand, including in rural ethnic communities, but the period for which it is exclusive is relatively short ${ }^{(4,10)}$. Detailed information on complementary feeding practices is limited. Past studies of child nutrition in the ethnic hill tribes have described poor quality and quantity of food intake, and some relevant local beliefs have been documented $^{(4,10,11)}$. In-depth exploration of local accounts for infant and young child feeding (IYCF) practices and the sociocultural context in which these are maintained has not been undertaken. However, research in other locations suggests that such an approach can provide valuable insights ${ }^{(12,13)}$.

A programme of research was undertaken with villagers in northern Thailand to inform the development of a locally tailored initiative to improve child nutrition ${ }^{(14)}$. The aim of the present study was to gain in-depth understanding of current IYCF practices, including accompanying perceptions and beliefs, and the sociocultural context of practices not aligned with WHO recommendations. As recommended by Pelto et al. ${ }^{(15)}$, the study was designed to draw out the complexity of these matters beyond that possible using a quantitative survey.

\section{Materials and methods}

A qualitative study was conducted in two Karen and two Lua ethnic hill tribe villages in the district of Mae Chaem, northern Thailand. These villages had already been chosen by the Knowledge Support Center for the Greater Mekong Sub-region (KSC-GMS) and the World Agroforestry Centre (ICRAF) in Chiang Mai as sites for an agricultural intervention. The villages are located at least $100 \mathrm{~km}$ from Mae Chaem, the nearest major city. Only one of the villages had an electricity supply. The number of households in the villages ranged from approximately fifty to 100 .

A workshop was held with local village health volunteers (VHV) in June 2014. The district public health officer invited two VHV from each village, where possible one male and one female; five men and three women attended. VHV are community members with basic training in health care, who support about ten households in relation to matters such as hygiene awareness and provision of medications.

The two-day workshop was designed to stimulate dialogue and to encourage participants to articulate their lived experiences around IYCF practices and their meanings, allowing different understandings to be shared and reflected upon ${ }^{(16)}$. First, a healthy child was explored: what this meant and what it required. Participants formed two groups to discuss this topic, with a facilitator providing guide questions. Discussion points were shared when the two groups recombined, to stimulate further dialogue. This arrangement was followed repeatedly over the workshop.

A short presentation on undernutrition, prevalence of stunting in hill tribe children and contributing factors was given. In the two groups, then as a whole group, participants responded to this information and were prompted to discuss IYCF practices. At appropriate points, WHO recommendations were invoked, for example: 'What does exclusive breast-feeding mean to you?' Complementary feeding was similarly addressed.

On the second day, participants completed a quiz about WHO IYCF recommendations which was designed to stimulate discussion of the answers, including areas where villagers' perspectives diverged. Prompt questions included: 'How could you explain to people what exclusive breast-feeding is?'

Subsequently, in-depth interviews were undertaken with two of the VHV who attended the workshop, eight other individuals with roles in the local health system, and twenty villagers. The villagers were selected by VHV, ensuring they were carers of children aged 0-5 years. Topics for the in-depth interviews were similar to those for the workshop but with greater opportunity for individuals to shape the direction and focus of dialogue. While interviews with villagers continued until data saturation appeared to be reached, the number of interviews with health workers and officials was limited by the number employed in the area.

The workshop was conducted in Thai by experienced bilingual (Thai/English) facilitators, under the direction of the first author. All interviews were facilitated by a translator. All relevant components of the workshop and all interviews were recorded and later concurrently transcribed and translated into English by the facilitators and translators. Transcriptions were reviewed by the first author with meanings of words clarified and the terminology across facilitators/translators iteratively checked for consistency in the use of translated terms. Participants' names have been changed for confidentiality.

Translated transcripts were coded and organized using the qualitative data analysis software NVivo 10 (QSR International Pty Ltd, Doncaster, Victoria, Australia). A detailed thematic analysis was conducted by the first author. Initially, specific words such as 'breast milk' and 'rice' were coded, as well as ages of children. Coding was gradually expanded to include specific feeding practices and explanations for them. Repeated patterns of meaning around IYCF practices (as well as exceptions) were then linked to the contextual factors invoked to support or legitimize them ${ }^{(17)}$. The analysis was guided by a social constructionist epistemology ${ }^{(18)}$ and was inductive and iterative, with the first author progressively presenting 
extracts and interpretations to the second and last author for discussion, mapping themes and their interrelationships. Understanding of transcripts was supplemented by observations from the first author's field notes, communication with the ICRAF team and with the Thai coauthors.

Prior to the workshop and the in-depth interviews, a participant information sheet was shared with villagers. Written informed consent was obtained from all participants. Participants received a small payment for their time.

\section{Results}

The workshop for VHV was attended by five men and three women, ranging in age from 24 to 38 years, all having at least one child of their own (see Table 1). Indepth interviews were subsequently undertaken with two of these VHV and with three district public health officers (PHO; range 30-48 years, one female), three community PHO (age range 29-45 years, one female) and two maternity nurses (both female, aged 25 and 32 years). Twenty other villagers were interviewed, two men and eighteen women, aged 20-42 years (see Table 2).

\section{Breast-feeding is widespread but not exclusive for 6 months}

All participants said that children in the villages were breastfed, in agreement with previous research ${ }^{(19)}$. Villagers saw breast-feeding as beneficial for the following reasons: 'prevention of painful nipple'; 'connecting with the child'; 'warmth'; 'protection against disease'; 'high immunity'; 'provision of all nutrition' (somboon); 'clean'; 'economical'; 'grow up quickly'; 'it provides strong health'; 'strength'; 'makes the child well natured and easy to teach' and 'will be intelligent'. These understandings echo previous findings about the value placed on breast milk throughout Thai society ${ }^{(20)}$.

\begin{tabular}{|c|c|c|}
\hline Indicator & $n$ & $\%$ \\
\hline \multicolumn{3}{|l|}{ Gender } \\
\hline Female & 3 & 38 \\
\hline \multicolumn{3}{|c|}{ Age group (years) } \\
\hline $21-25$ & 1 & 13 \\
\hline $26-30$ & 3 & 38 \\
\hline $31-35$ & 2 & 25 \\
\hline $36-40$ & 2 & 25 \\
\hline \multicolumn{3}{|l|}{ Occupation } \\
\hline Farmer & 6 & 75 \\
\hline Other & 2 & 25 \\
\hline
\end{tabular}

Breast-feeding was rarely exclusive for 6 months. Villagers' understanding of EBF varied but, in general, EBF was not distinguished from other modes of breast-feeding. There seemed to be a common perception that breast milk was important, but exclusivity did not matter:

'Maybe good give only milk of mother ... up to the child some one and a half years some two year [give only milk of mother] ... not sure doctor said 6 months.' (Noin, mother)

'One problem that mothers have is that when asked they are confused between exclusive breast-feeding and normal breast-feeding and mothers say yes, yes we give breast-feeding, but in between they are giving water.' (PHO1)

Non-EBF was due to the cultural practice of feeding water or to early introduction of rice or both. Water was reported to be given by most mothers from as early as 1 month. The amount of water was reported to be the 'tip of [a] teaspoon', given to help 'wash out' milk and/or rice from the throat and prevent 'dry throat'. Predominant breastfeeding (breast milk and other liquids) is common practice in Thailand ${ }^{(21)}$ and other parts of Asia ${ }^{(22-24)}$.

\section{Introduction of complementary foods before 6 months}

Rice was introduced as early as 1 month and almost always within the first 3 months:

'I will give rice one time a day ... [because] the baby is crying and [will] not sleep. The people in the past, once they are born they just eat rice ... like for them when they were born their parents immediately gave them rice.' (Sarn, father)

Table 2 Characteristics of the villagers ( $n$ 20) interviewed in the present qualitative study on infant and young child feeding practices, accompanying beliefs and their sociocultural context conducted in two Karen and two Lua ethnic hill tribe villages in the district of Mae Chaem, northern Thailand, June 2014

\begin{tabular}{lrr}
\hline Indicator & $n$ & $\%$ \\
\hline Gender & & \\
$\quad$ Female & 18 & 90 \\
Age group (years) & & \\
$\quad \leq 20$ & 2 & 10 \\
$21-25$ & 8 & 40 \\
$26-30$ & 6 & 30 \\
$31-35$ & 2 & 10 \\
$36-40$ & 1 & 5 \\
$41-45$ & 1 & 5 \\
Occupation & & \\
Farmer & 19 & 95 \\
Other & 1 & 5 \\
No. of children aged 0-5 years & & \\
1 & 10 & 45 \\
2 & 7 & 32 \\
3 & 5 & 23 \\
\hline
\end{tabular}


The early introduction of rice is consistent with previous studies conducted throughout Thailand ${ }^{(4,21,25)}$.

As illustrated in the quotes that follow, villagers often referred to a need to supplement breast milk with rice from approximately 3 months, due to a belief that breast milk was not sufficient as the child grew. The view that in the mountains mothers could not make sufficient breast milk, leaving the child hungry, appeared to be widespread. Rice was seen to strengthen the child (although it was unclear if it was seen to be nutritionally equivalent to breast milk):

'If [we] stay long time in the city then [we are] able to [give only breast milk for 6 months], but up here in the mountains [we do] not have complementary food [referring to food that goes with rice] ... The milk will not be full of all the different [food] groups up on the mountain.' (Maew, mother and VHV)

'Grandparents looking after [the child] give rice at 3 or 4 months because the child is hungry as the mother's milk is not sufficient.' (Maew, VHV and mother)

'[Rice] has benefits. [I] give [it to my] child and [it] helps them grow if [my] child [does] not eat [it they] will be very thin and not strong.' (Fan, mother)

It was also common for villagers to report that they fed children rice earlier than recommended, to prepare them for later feeding:

'The grandparents said that if I don't give rice in the beginning, then the child will not want to eat rice when they grow up.' (Duk, father)

This concern appeared to be particularly related to the circumstance that the mother 'may not be able to go to work' if the child relies only on breast milk. The early introduction of complementary food built familiarity, and thus facilitated the mother's return to work:

'At birth the doctor said drink only breast milk for 6 months and then eat rice/food ... Mash rice, make mash and give in the first month just one meal to practice eat then second month two meals and third month three meals. The child to practice because in the mountains [we do] not have complementary food [appears to be referring to infant formula].' (Geb, mother)

Worldwide, the perception of insufficient breast milk is the most common reason for early supplementation and/or discontinuation of breast-feeding ${ }^{(26,27)}$. Past reasons described for early introduction of rice in Thailand have included following traditional practice ${ }^{(28,29)}$ as well as insufficient breast milk ${ }^{(21,30)}$. Our work draws attention to the contextual significance of giving the child rice, which we now elaborate on.

\section{Mothers return to work within a few months of giving birth}

Some mothers returned to working in the fields as early as 1 month after birth but more often this was reported to occur from 3 months. This is similar to other rural, agricultural communities in Vietnam ${ }^{(31)}$. The time often corresponded to when the villagers felt the child was able to stay with another carer. Only one mother mentioned that she took her child to the field with the aid of another family member. Most mothers did not take their children to the field due to the labouring requirements, 'weather' and 'difficult' conditions. The time spent away from the child progressively increased, resulting in an increase in complementary feeding and a decrease in breast-feeding:

'Give milk in the morning and go for half a day then need to return as have so much milk.' (Yang, mother)

Mothers returning to farming work was usually seen as a necessity. It was a duty accepted without question:

'I must go back to work ... [I] do not have anyone to help with work ... [parents] they are too old.' (Raw, mother)

'I feel I can [stay at home for first 6 months] but my husband goes [to work] alone and he will be tired, so we have to help each other. When we are going [to work] we are not harming our child ... we are doing it to raise him up.' (Tiang, mother)

Pelto et $a l .{ }^{(15)}$ have drawn attention to the demands on women's time, and specifically the heavy workloads for women in subsistence farming communities, as a major impediment to being able to care for their children through EBF for 6 months and appropriate complementary feeding. This has been described as women 'balancing' or 'reconciling' competing responsibilities. However, the strong cultural consensus around these arrangements makes it unlikely that it is a conscious process in the way these terms may suggest. In his theory of social practice, the sociologist Bourdieu proposes that as individuals grow up in a community, they are imbued with a set of dispositions and expectations, commensurate with their status $^{(32)}$. In this way, an apparent fit develops between a person's expectations and their circumstances. Thus, women in the hill tribes accept that they must physically labour and that those who are older should look after infants and young children.

\section{Duration of breast-feeding often to 2 years}

The total duration of breast-feeding was variable although there were many reports of breast-feeding continuing beyond the child reaching age 2 years of age. Mothers stopped breast-feeding in various ways, often by using deterrents, such as plasters, medicine or other substances 
placed on the breasts. The need for independence to complete daily activities was often reported as the reason for ceasing breast-feeding:

'If it is convenient for the mother, then that's okay [to continue to breast-feed]. But it's also related with the mother. Like the mother, myself, I need to go to a meeting, and [if] the child is attached to breast milk, then I can't leave my child.' (Maew, mother and VHV)

Other reasons also given for ceasing breast-feeding included the belief that the child was old enough to stop, painful breasts, and fears of poor child growth due to filling up on breast milk.

\section{Infant formula is desired but in limited use}

Most villagers had heard about formula or seen it in nearby cities. Formula was generally desired by families, but its use was limited:

'I used to be in Chiang Mai looking after children and saw them eating formula, so that is how I know [about formula] - so I want to give [formula] to my own kids.' (Sod, mother)

Some participants were aware that breast milk was preferable to formula:

'I think by receiving only mother's milk, the child's immunity should be more than formula milk that is sold. [Breast milk] already has complete nutrients ... if we give breast milk ... the child will get the warmth ... and the love.' (Maew, mother and VHV)

The major limitation on the use of formula was its affordability. A mother talked of how she wanted to feed formula to her three children, but she did 'not have the money to buy [it]' (Sod, mother).

A VHV reported on how some villagers would dilute formula, to extend it:

'They're also very poor. They buy formula milk. But for 4 ounces, they put only one or two spoonfuls.'

(Kip, mother and VHV)

Undernutrition from diluting formula is a recognized problem in many countries ${ }^{(8)}$. The current study was not designed to quantify the extent of formula use or its contribution to malnutrition, but it does not appear to be a notable contributor.

\section{Little variety in transitional foods}

Variety in complementary foods was not provided until much later than the WHO-recommended time of around 6 months $^{(8)}$. Rice and banana, occasionally egg, were given to children from 3 to 12 months. Vegetables and meat were rarely said to be given to children under 12 months of age. Absence or provision of these foods was predominantly related to perceptions of children's readiness to eat different foods:

'From the age of 3 years, they should be able to start eating these vegetables [referring to a range of vegetables].' (Aek, father and VHV)

Villagers often reported introducing a food when the child could eat it independently:

'When he wants to eat and can ask for food and eat by himself.' (Song, mother)

This agrees with previous reports ${ }^{(4,10)}$. One mother reported that she will start meat at 9-10 months as that is when the child 'starts to have teeth' (Noin, mother).

Most villagers provided young children with foods that had suitable textures that did not require modification, limited in number. One exception was described by a mother of a 17-month-old:

'I make the meat using a strainer and a bottle to press against it to make it small and the meat I would cut into small small pieces and put it into rice porridge to just give it flavour.' (Yang, mother)

The mother indicated that other carers may not do this as 'maybe it is too much work'.

Pelto et $a l{ }^{(15)}$ describe a spectrum of approaches to complementary feeding, from 'controlling' through to 'disengaged'. These authors affirm that when children are expected to eat independently from an early age and there is little preparation of complementary foods, children are likely to be malnourished, especially between 6 and 12 months. The underlying issue, again, is seen to be the other demands on women's time. In the hill tribes, widespread cultural agreement that complementary feeding should not be time-consuming fits with the expectation that mothers will labour to maintain household livelihood.

Villagers relied heavily on the foods available within and around the villages. This was necessary in view of geographic remoteness, seasonal impassability of roads and the cost of buying food in the nearest city:

'The nutrition [villagers] might not be so aware about, they eat just what they have ... the people here just get by, they try to eat what they can, but it is usually just the same old foods.' (PHO1)

Rice and banana for infants were seen as available and affordable. At five baht each, eggs were seen as relatively expensive:

'The problem with the hill tribe people is that they do not have the money. So I can tell them, "All you need to do is give your child one egg a day and then your child is getting all this protein." And they are like "Yes, we know, but we don't have the money to buy the eggs, so what are we going to do?"' (PHO1) 
A subtext of poverty and food insecurity is woven through these accounts. This underscores the point made by Pelto et $a l .{ }^{(15)}$, among others, that improving complementary feeding depends on availability or access to appropriate foods as well as information.

A number of other factors were sporadically mentioned as constraining food choice for infants. One was fear of choking. For example, one mother of an 8-month-old said she avoided other food because:

'When they mash rice with other food this gets stuck in the throat.' (Song, mother)

According to a VHV, vegetables may be delayed due to belief they caused diarrhoea:

'7-8 [months], not yet [give vegetables]. We're afraid they'll get diarrhoea. If they get diarrhoea, it'll be really troublesome.' (Maew, mother and VHV)

A few villagers mentioned concerns about pesticides on vegetables that were thought to cause diarrhoea.

The villagers have been exposed to campaigns to increase their awareness about worms. Worms were sometimes thought to be associated with consuming meat and vegetables:

'Seventy per cent of the kids have [worms]. About over 10 years ago another survey [was] done in [village] and 80 to $90 \%$ of children [had worms].' (PHO2)

'If I give meat I am scared the child will get worms and it is difficult to eat worm medicine as he is still too young.' (Sarn, father)

Underpinning the concerns about choking, diarrhoea and worms was the distance to medical facilities, and therefore the potential risks to health and life:

'The people in the mountains they don't dare take a risk ... because they see the danger of the hospital being really so far.' (Noom, father and VHV)

Not only the distance was seen as a barrier, but also complicating factors of difficult terrain, needing a vehicle and driver, and the ability to speak Thai.

\section{Information on infant and young child feeding may not be accessible}

Currently, pregnant women receive information about IYCF in the Maternal and Child Health Book given at their first antenatal visit which is usually at the nearest public health office. The 'pink book' includes information with supporting pictures; however, the pictures rely on understanding detailed Thai explanations. Thai is rarely spoken within the villages. One PHO reported: 'The problem here is the language because they are all hill tribes'. The first author clarified: 'So do the women understand Thai?' and the answer was 'mostly not'.
Breast-feeding information in the 'pink book' includes the benefits of breast-feeding along with proper attachment and positioning and how to express. Complementary foods are explained including examples and portion sizes. No one was reported to formally verbally share complementary feeding information:

'No one really has the duty to tell them [carers] that, [what foods to feed after 6 months] but they already know it. It is more like common sense - eat soft food - that is what they are doing anyways.' (PHO3)

These findings agree with villagers reporting that they were 'not recommended' anything about complementary feeding.

\section{Discussion}

The present study explored IYCF practices and their meanings among hill tribe communities in northern Thailand. The study confirmed poor adherence to WHO IYCF recommendations, as reported previously ${ }^{(4,10)}$, but also drew out the sociocultural context for current views and practices. Key findings of the study are that EBF was impeded by the need for mothers to return to work, with infants usually cared for by older adults who would feed them water and rice mixtures instead of breast milk. Complementary foods were introduced earlier than 6 months, typically what children could eat with little preparation, and food variety was limited, reflecting local contingencies.

Women's work is a common barrier to EBF in rural communities in Thailand ${ }^{(4,10,21,30,33)}$ and nearby countries ${ }^{(24,31,34)}$. The issue of other demands on women's time undermining IYCF arose repeatedly in the review of sixteen case studies undertaken by Pelto et $a l^{(15)}$. Women who were subsistence farmers were specifically mentioned as having heavy workloads.

Pelto et $a l .^{(15)}$ trace the history of the concept of care in relation to IYCF, incorporated into the UNICEF framework for the determinants of nutrition in $1990^{(35)}$, and elaborated on since ${ }^{(36,37)}$. In the framework, inadequate maternal and child care is seen as an 'underlying' determinant of nutrition, on the same level as household food insecurity, unhealthy environments and lack of health services; the designated 'basic' determinants are economic, political and ideological.

For women in the hill tribes, caring for infants is displaced by work to ensure the livelihood of the household. The entrenched mode of household economic organization makes physical labour by women, within a relatively short time of giving birth, a culturally sanctioned duty. To be able to care through IYCF, women need time as well as support from the community (e.g. to redistribute workload) and greater autonomy; these are aspects of empowerment ${ }^{(38)}$. Cunningham et al. ${ }^{(39)}$ speculate that 
control over workload is especially important when children are very young.

Subsistence farmers work very hard in conditions of poverty, as reported for rural communities throughout Asia $^{(31)}$. In a 2002 World Alliance for Breastfeeding Action forum, Menon ${ }^{(40)}$ drew attention to the role of globalization in further impoverishing people, especially women, in developing countries. Women who had historically survived by fostering subsistence economies have had their meagre livelihoods undermined as land is commercialized, cash crops are introduced and subsidized imported produce is 'dumped'. The increasing struggle to meet basic needs was recognized as inhibiting breast-feeding and as difficult to address without attending to women's empowerment.

Indigenous women in the Bolivian Andes, as described by Jones et al. ${ }^{(41)}$, face similar problems. Farming and herding are a heavy burden for these women, leaving only a small amount of time for household chores and food preparation, and there was low diversity of foods appropriate for infants. Jones et al. ${ }^{(41)}$ caution against targeting women with behaviour change communication strategies in the absence of changing the sociocultural constraints on food availability and livelihood security. This principle is widely recognized ${ }^{(15,42,43)}$. While agricultural solutions appear promising, Jones et al. ${ }^{(41)}$ draw attention to the important matter that such interventions should not create further work for women farmers. Efforts are needed to 'purposively transform caregiving environments and guide time use decisions toward child and maternal care, ${ }^{,(41)}$ (p. 1682), with the support of the whole community.

The appropriateness of collective parenting, at least before a child is 6 months old, is thus called into question $^{(44)}$. Collective parenting is commonly seen in remote indigenous communities ${ }^{(4,13,45-48)}$. As apparent in the present study, remoteness also means that outside influences, other views and new information are encountered only sporadically and therefore local knowledge carries most weight. Grandmothers are thus both involved in child care and a trusted source of information ${ }^{(13,31,41,45,49,50)}$, reinforcing certain beliefs and practices that make collective parenting possible but are counterproductive for IYCF.

In such contexts, interventions should be sensitive to collective responsibility for parenting ${ }^{(51)}$ and care is needed so as not to break trusted ties within a community ${ }^{(52)}$. For example, Aubel et al. ${ }^{(45)}$ described providing nutrition education to grandmothers in Senegal and encouraging them to promote good nutritional practices related to pregnancy and infant feeding. For the hill tribes, a first step could entail translating the 'pink book' into the local language with lots of pictures to enhance understanding and sections that are specifically designed for grandmothers.

Along with the obligations on women, remoteness and poverty underlie the IYCF practices described by the hill tribe communities. There are seasonal variations in water supply and road traversability, with access to health and other services limited ${ }^{(53)}$. Improvements in infrastructure to decrease remoteness have been associated with improvements in nutrition elsewhere in Thailand and in South Asian countries as part of integrated and intersectoral programmes ${ }^{(54-56)}$.

As part of an initiative to improve child nutrition in the hill tribe communities, it has been proposed to trial a nutrition-sensitive agriculture intervention, involving giving families chickens and seeds for homestead gardens, accompanied by nutritional education ${ }^{(57)}$. From accounts in the present study, eggs are culturally appropriate, already seen to be suitable for IYCF. Gardens could enable women to work closer to home, but more direct efforts, such as cash or food transfers to enable women to remain at home for 6 months and a village-level complementary feeding programme ${ }^{(58)}$, may be required to change longstanding household arrangements and women's roles. Furthermore, other nutrition-sensitive initiatives may be worth investigating in the hill tribes ${ }^{(58)}$.

A limitation of the study was that the researchers were outsiders, although the Thai co-authors have detailed knowledge of the hill tribe communities. To address this, perspectives were sought from a range of people with different roles in the local health system and villagers were included until saturation appeared to occur. Villagers were interviewed in Thai, which was their second language, and this may have prevented full expression of their perspectives. However, interviews were generally unhurried and the translators understood the need for villagers to find the words they wanted, sometimes with help from other family members, often men (who were more fluent in Thai). Grandmothers' views were often obtained with assistance from parents, which again may have affected what was said, but on the other hand grandmothers are respected authorities on the care and feeding of children. We acknowledge that interpretations of translated accounts have been made, and these will be influenced by our theoretical and epistemological stances ${ }^{(17)}$. To reduce this form of bias, the analysis was undertaken in sections with three researchers repeatedly reflecting on the integrity of the interpretation, following which the entire analysis was considered by two Thai academics.

Further research with these communities could provide other insights into the child nutrition situation. For example, research with a specific focus on grandmothers or on men, especially those with leadership roles, would be useful. It may be possible to compare feeding practices for stunted and non-stunted children. Flowing from the present study, it would be worth exploring arrangements by which women might be relieved from work for 6 months following birth of a child and how support for this could be built.

\section{Conclusion}

In conclusion, the present study draws out the ways in which underlying factors that feature in the UNICEF 
framework ${ }^{(35)}$ form a nexus that perpetuates poor nutrition in children in the hill tribe communities. Cultural practices and beliefs are shaped by what is possible ${ }^{(32)}$, as illustrated here. This reinforces the need to address underlying determinants in order to create possibilities for changing practices and collective meaning making. Determinants include the heavy burden of work on childbearing women in the poor, remote villages, along with other structural barriers that contribute to lack of food availability and low diversity.

\section{Acknowledgements}

Acknowledgements: The authors thank all participants including the villagers, public health officers, village health volunteers and nursing staff at Mae Chaem Hospital. They also thank the following for advice and practical assistance: Posri Leelaprat, Dr Sakda Pruenglampoo and Somluck Nimsakul from the Research Institute for Health Sciences; Pailin Limwattanachai, Golbang Jafari, Surachet Jinakeaw, Palika Champrasert, Anantika Ratnamhin, Natjan Chairat and Tanawit Wongsur from KSC-GMS/ICRAF; Dr Peter Berti of HealthBridge, Canada; and Dr Chawapornpan Chanprasit and Dr Ari Patcharaporn from Chiang Mai University. Financial support: This research received no specific grant from any funding agency in the public, commercial or notfor-profit sectors. Conflict of interest: A.R. was supported by a scholarship from the Faculty of Health and Medical Sciences, University of Adelaide, and a Prime Minister's Australia-Asia Scholarship. In-kind support was provided by KSC-GMS, ICRAF and the Research Institute of Health Sciences within Chiang Mai University. P.Wa. from KSC-GMS and ICRAF was involved in the study design, conduct of the study and preparation of the manuscript. Two members of the Research Institute of Health Sciences were involved in the study design and the conduct of the study. Authorship: Formulation of the research question: A.R., V.M., L.G.S., P.Wa. and P.Wi. Study design: A.R., V.M., L.G.S., P.Wa. and P.Wi. Carrying out the study: A.R. Analysing the data: A.R., V.M. and L.G.S. Writing the article: A.R., V.M., L.G.S., P.Wa. and P.Wi. Ethics of human subject participation: This study was conducted according to the guidelines laid down in the Declaration of Helsinki and all procedures involving human subjects were approved by the University of Adelaide, Australia (HREC\# H-2014-51) and the Research Institute of Health Sciences, Thailand (study code 4/57). Written informed consent was obtained from all subjects.

\section{References}

1. World Health Organization \& UNICEF (2008) Strengthening Action to Improve Feeding of Infants and Young Children 6-23 Months of Age in Nutrition and Child Health Programmes, Geneva, 6-9 October 2008: Report of Proceedings. Geneva: WHO.
2. Tienboon P \& Wangpakapattanawong P (2007) Nutritional status, body composition and health conditions of the Karen hill tribe children aged 1-6 years in northern Thailand. Asia Pac J Clin Nutr 16, 279-285.

3. Mongkolchati A, Thinkhamrop B, Mo-Suwan L et al. (2010) Prevalence and incidence of child stunting from birth to two years of life in Thai children: based on the Prospective Cohort Study of Thai Children (PCTC). J Med Assoc Thai $\mathbf{9 3 ,}$ 1368-1378.

4. Chotiboriboon S, Tamachotipong S, Sirisai S et al. (2009) Thailand: food system and nutritional status of indigenous children in a Karen community. In Indigenous Peoples' Food Systems: The Many Dimensions of Culture, Diversity and Environment for Nutrition and Health, pp. 158-183 [FAO and Centre for Indigenous Peoples' Nutrition and Environment, editors]. Rome: FAO.

5. Mae Chaem Public Health Office (2013) Anthropometric Data for Mae Chaem Children Aged 0-5 Years, Third Quarter (in Thai). Mae Chaem: Ministry of Health.

6. Rojroongwasinkul N, Kijboonchoo K, Wimonpeerapattana W et al. (2013) SEANUTS: the nutritional status and dietary intakes of 0.5-12-year-old Thai children. Br J Nutr 110, Suppl. 3, S36-S44.

7. Isvilanonda S \& Bunyasiri I (2009) Food Security in Thailand: Status, Rural Poor Vulnerability, and Some Policy Options. Bangkok: Kasetsart University.

8. Dewey K (2003) Guiding Principles for Complementary Feeding of the Breastfed Child. Washington, DC: PAHO.

9. World Health Organization (2005) Guiding Principles for Feeding Non-Breastfed Children 6-24 Months of Age. Geneva: WHO.

10. Chanprasit C (1991) Young children in a rural area of Chiang Mai, northern Thailand. Master's Thesis, University of Western Australia.

11. Tienboon $\mathrm{P}$, Wangpakapattanawong $\mathrm{P}$, Thomas $\mathrm{D}$ et al. (2008) Dietary intakes of Karen hill tribe children aged 1-6 years in northern Thailand. Asian Pac J Trop Med 1, 1-6.

12. Aubel J (2012) The role and influence of grandmothers on child nutrition: culturally designated advisors and caregivers. Matern Child Nutr 8, 19-35.

13. Arts M, Geelhoed D, De Schacht C et al. (2010) Knowledge, beliefs, and practices regarding exclusive breastfeeding of infants younger than 6 months in Mozambique: a qualitative study. J Hum Lact 27, 25-32.

14. Berti PR, Desrochers RE, Hoi Van P et al. (2016) The process of developing a nutrition-sensitive agriculture intervention: a multi-site experience. Food Secur 8, 1053-1068.

15. Pelto GH, Levitt E \& Thairu L (2003) Improving feeding practices: current patterns, common constraints, and the design of interventions. Food Nutr Bull 24, 45-82.

16. Liamputtong P (2009) Focus groups. In Qualitative Research Methods, 3rd ed., pp. 64-86 [P Liamputtong, editor]. Oxford: Oxford University Press.

17. Braun V \& Clarke V (2006) Using thematic analysis in psychology. Qual Res Psychol 3, 77-101.

18. Ellingson L (2011) Analysis and representation across the continuum. In The Sage Handbook of Qualitative Research, 4th ed., pp. 595-612 [NK Denzin and YS Lincoln, editors]. Los Angeles, CA: SAGE Publications, Inc.

19. Wangpakapattanawong P \& Pruenglampoo S (2016) Nutrition-Sensitive Agricultural Intervention and Impact in Mae Chaem District, Chiang Mai Province, Thailand. Chiang Mai: Knowledge Support Center-Greater Mekong Sub-region.

20. Liamputtong P \& Kitisriworapan S (2011) Good mothers and infant feeding practices amongst women in northern Thailand. In Infant Feeding Practices, pp. 141-159 [P Liamputtong, editor]. New York: Springer. 
21. Winichagoon P (2013) Thailand nutrition in transition: situation and challenges of maternal and child nutrition. Asia Pac J Clin Nutr 22, 6-15.

22. de Sa J, Bouttasing N, Sampson L et al. (2013) Identifying priorities to improve maternal and child nutrition among the Khmu ethnic group, Laos: a formative study. Matern Child Nutr 9, 452-466.

23. Duong DV, Binns CW \& Lee AH (2005) Introduction of complementary food to infants within the first six months postpartum in rural Vietnam. Acta Paediatr 94, 1714-1720.

24. Locks LM, Pandey PR, Osei AK et al. (2015) Using formative research to design a context-specific behaviour change strategy to improve infant and young child feeding practices and nutrition in Nepal. Maternal Child Nutr 11, 882-896.

25. Shevasant S, Sujumnonk P \& Stoeckel J (1987) Determinants of 'Risk Factors' Associated with Infant and Child Morbidity and Mortality among the Karen Hilltribe Population of Northern Thailand. Bangkok: Population Council; available at http://www.popline.org/node/347954

26. Dykes F \& Williams C (1999) Falling by the wayside: a phenomenological exploration of perceived breast-milk inadequacy in lactating women. Midwifery 15, 232-246.

27. Fewtrell MS, Morgan JB, Duggan C et al. (2007) Optimal duration of exclusive breastfeeding: what is the evidence to support current recommendations? Am J Clin Nutr 85, issue 2, 635S-638S.

28. Jackson DA, Imong SM, Wongsawasdii L et al. (1992) Weaning practices and breast-feeding duration in Northern Thailand. Br J Nutr 67, 149-164.

29. Tontisirin K \& Winichagoon P (1999) Community-based programmes: success factors for public nutrition derived from the experience of Thailand. Food Nutr Bull $\mathbf{2 0}$, 315-322.

30. Yimyam S (2011) Breastfeeding beliefs and practices among employed women: a Thai cultural perspective. In Infant Feeding Practices, pp. 125-140 [P Liamputtong, editor]. New York: Springer.

31. Dearden KA, Quan LN, Do M et al. (2002) Work outside the home is the primary barrier to exclusive breastfeeding in rural Vietnam: insights from mothers who exclusively breastfed and worked. Food Nutr Bull 23, 99-106.

32. Bourdieu P (1977) Outline of a Theory of Practice. Cambridge: Cambridge University Press.

33. Yimyam S \& Morrow M (1999) Breastfeeding practices among employed Thai women in Chiang Mai. J Hum Lact 15, 225-232.

34. Popkin BM, Adair L, Akin JS et al. (1990) Breast-feeding and diarrheal morbidity. Pediatrics 86, 874-882.

35. UNICEF (1990) Strategy for improved nutrition of children and women in developing countries. Indian J Pediatr 58, $13-24$.

36. Black RE, Allen LH, Bhutta ZA et al. (2008) Maternal and child undernutrition: global and regional exposures and health consequences. Lancet 371, 243-260.

37. Gillespie S \& McLachlan MRS (2003) Combating Malnutrition: Time to Act. Washington DC: The World Bank.

38. Smith LC, Ramakrishnan U, Ndiaye A et al. (2003) The importance of women's status for child nutrition in developing countries. Food Nutr Bull 24, 287-288.

39. Cunningham K, Ruel M, Ferguson E et al. (2015) Women's empowerment and child nutritional status in South Asia: a synthesis of the literature. Maternal Child Nutr 11, 1-19.

40. Menon L (2002) Need to address women's issues to promote breastfeeding. In Proceedings of the WABA Global Forum 2: Nurturing the Future: Challenges to Breastfeeding in the 21st Century, Arusha, Tanzania, 23-27 September 2002, pp. 1-8. Penang: World Alliance for Breastfeeding Action.

41. Jones AD, Agudo YC, Galway L et al. (2012) Heavy agricultural workloads and low crop diversity are strong barriers to improving child feeding practices in the Bolivian Andes. Soc Sci Med 75, 1673-1684.

42. Horton S (1999) Opportunities for investments in nutrition in low-income Asia. Asian Dev Rev 17, 246-273.

43. Stewart CP, Iannotti L, Dewey KG et al. (2013) Contextualising complementary feeding in a broader framework for stunting prevention. Maternal Child Nutr 9, 27-45.

44. Lewig K, Arney F \& Salveron M (2010) Challenges to parenting in a new culture: Implications for child and family welfare. Eval Program Plann 33, 324-332.

45. Aubel J, Touré I \& Diagne M (2004) Senegalese grandmothers promote improved maternal and child nutrition practices: the guardians of tradition are not averse to change. Soc Sci Med 59, 945-959.

46. Bezner Kerr R, Berti PR \& Chirwa M (2007) Breastfeeding and mixed feeding practices in Malawi: timing, reasons, decision makers, and child health consequences. Food Nutr Bull 28, 90-99.

47. Kakute PN, Ngum J, Mitchell P et al. (2005) Cultural barriers to exclusive breastfeeding by mothers in a rural area of Cameroon, Africa. J Midwifery Womens Health 50, 324-328.

48. Semega-Janneh IJ, Bøhler E, Holm H et al. (2001) Promoting breastfeeding in rural Gambia: combining traditional and modern knowledge. Health Policy Plan 16, 199-205.

49. Bezner Kerr R, Dakishoni L, Shumba L et al. (2008) 'We grandmothers know plenty': breastfeeding, complementary feeding and the multifaceted role of grandmothers in Malawi. Soc Sci Med 66, 1095-1105.

50. Delgado E, Sorensen S \& Van der Stuyft P (1994) Health seeking behaviour and self-treatment for common childhood symptoms in rural Guatemala. Ann Soc Belg Med Trop 74, 161-168.

51. Davey S, Davey A, Adnish SV et al. (2015) Study of impact of sociocultural and economic factors of mothers on the nutritional status of their malnourished children in a rural area of Delhi, India. Int J Med Sci Public Health $\mathbf{4}$, $162-167$

52. Millard AV (1990) The place of the clock in pediatric advice: rationales, cultural themes, and impediments to breastfeeding. Soc Sci Med 31, 211-221.

53. Wakerman J \& Lenthall S (2002) Remote health. In The New Rural Health, pp. 126-148 [D Wilkinson and I Blue, editors]. Oxford: Oxford University Press.

54. Cattaneo A \& Quintero-Romero S (2006) Protection, promotion and support of breastfeeding in low-income countries. Semin Fetal Neonatal Med 11, 48-53.

55. Headey D, Hoddinott J \& Park S (2016) Drivers of nutritional change in four South Asian countries: a dynamic observational analysis. Matern Child Nutr 12, 210-218.

56. Heaver R \& Kachondam Y (2002) Thailand's National Nutrition Program: Lessons in Management and Capacity Development. Washington, DC: The International Bank for Reconstruction and Development/The World Bank.

57. Berti PR, Krasevec J \& FitzGerald S (2004) A review of the effectiveness of agriculture interventions in improving nutrition outcomes. Public Health Nutr 7, 599-609.

58. Ruel MT \& Alderman H, Maternal Child Nutrition Study Group (2013) Nutrition-sensitive interventions and programmes: how can they help to accelerate progress in improving maternal and child nutrition? Lancet 382, 536-551. 